\section{ISOLATION AND IDENTIFICATION OF CHLORAMPHENICOL FROM THE MOON SNAIL, LUNATIA HEROS}

\author{
Catherine A. Price a), Sr. Eva Maria Lynch ${ }^{a}$, \\ Betty AnNe Bowie ${ }^{\text {b) }}$ and David J. Newman ${ }^{\text {b)* }}$ \\ ${ }^{2}$ Department of Biology, Chestnut Hill College, \\ Philadelphia, PA 19118 \\ ${ }^{\mathrm{b}}$ Department of Microbiology, Smith Kline \& \\ French Laboratories, P.O. Box 7929, \\ Philadelphia, PA 19101, U.S.A.
}

(Received for publication October 8, 1980)

Of the 3,500 or more antibiotics isolated from various organisms, only a few are derived from marine organisms ${ }^{1)}$. These biologically active metabolites from marine organisms are predominantly toxins of various chemical structures. In this paper, we report the isolation and identification of chloramphenicol from the moon snail, Lunatia heros.

Moon snails, obtained from the Marine Biological Laboratories, Woods Hole, MA, as live specimens in sea water, were deshelled, minced in a Waring blender, frozen and then thawed slowly at room temperatures. The thawed mince after three cycles of this freeze-thaw process was treated with ethanol to a $70 \% \mathrm{v} / \mathrm{v}$ final concentration (at $4{ }^{\circ} \mathrm{C}$ ). The precipitate was discarded and the aqueous-ethanol supernatant solution flash-evaporated. The resulting residue was then dissolved in water $(\mathrm{pH} 6.5)$ and frozen for further investigation.

The material recovered from the moon snails inhibited both Gram-positive and Gram-negative microorganisms. A further check of the anti- bacterial activity, using a battery of antibiotic resistant strains ${ }^{2)}$, indicated an activity profile resembling chloramphenicol.

The antibacterial material was further purified as follows. The crude aqueous extract was extracted twice at $\mathrm{pH} 6.5$ with five volumes of ethyl acetate. The organic phases were separated from the aqueous phase, combined and dried over anhydrous sodium sulfate. The ethyl acetate extract was flash evaporated at less than $35^{\circ} \mathrm{C}$ and the residue dried by lyophilization to yield a yellow-white amorphous powder.

In all subsequent assays, chloramphenicol at $1 \mathrm{mg} \cdot \mathrm{ml}^{-1}$ in methanol was used as a standard. The dried extract was dissolved at $1 \mathrm{mg} \cdot \mathrm{ml}^{-1}$ in anhydrous methanol and chromatographed in the systems shown in Table 1. Biologically active material was detected with Bacillus subtilis (ATCC 6633). Chloramphenicol was also detected on silica gel plates by spraying with acidic stannous chloride followed by $p$-dimethylaminobenzaldehyde as described by AKAGAWA et al. ${ }^{3)}$.

Based on the profile of antibacterial activity, the chromatographic data in seven systems and the reaction with the AKAGAwA staining technique, the antibiotic isolated from the moon snail was identified as chloramphenicol, present at a level of approximately $4 \mathrm{mg}$ per $100 \mathrm{~g}$ wet weight of original mince. This identification was confirmed by a comparison of the high-resolution infrared spectrum of the extract with that of authentic chloramphenicol run under the same conditions in a Perkin-Elmer Model 299 spectrometer. Coincident peaks were obtained between the extract and chloramphenicol throughout the spectrum from 4,000 to $600 \mathrm{~cm}^{-1}$.

In order to confirm that chloramphenicol could

Table 1. Chromatography of Lunatia heros extract.

\begin{tabular}{|c|c|c|c|c|}
\hline Support & Direction /Time & Solvents & $\underset{\text { (Extract) }}{\mathrm{Rf}}$ & $\begin{array}{c}\mathrm{Rf} \\
\text { (Chloramphenicol) }\end{array}$ \\
\hline Whatman $\# 1$ & Descending/3 hours & Water & 0.71 & 0.73 \\
\hline Whatman $\# 1$ & Descending/14 hours & Water saturated with $n$-butanol & 0.79 & 0.82 \\
\hline Whatman $\# 1$ & Descending/3 hours & $3 \% \mathrm{w} / \mathrm{v}$ aqueous $\mathrm{NH}_{4} \mathrm{Cl}$ & 0.74 & 0.73 \\
\hline Whatman $\# 1$ & Descending/14 hours & $\begin{array}{l}\text { n-Butanol-water - methanol } \\
\text { v/v } 4: 1: 2\end{array}$ & 0.80 & 0.81 \\
\hline Whatman $\# 1$ & Ascending $/ 2.5$ hours & Benzene-methanol v/v $4: 1$ & 0.47 & 0.49 \\
\hline $\begin{array}{l}\text { Silica gel } \\
\quad \text { (Quanta LQDF) }\end{array}$ & Ascending/1.5 hours & $\begin{array}{l}\text { Methanol-methylenedichloride } \\
\mathrm{v} / \mathrm{v} 7: 93\end{array}$ & 0.40 & 0.40 \\
\hline $\begin{array}{l}\text { Silica gel } \\
\quad \text { (Quanta LQDF) }\end{array}$ & Ascending/ 1.5 hours & $\begin{array}{l}\text { Methanol-methylenedichloride } \\
\text { v/v } 20: 80\end{array}$ & 0.88 & 0.90 \\
\hline
\end{tabular}


be extracted from Lunatia heros and that the antibiotic was not an artefact of isolation or treatment, we obtained fresh animals from the Marine Biological Laboratories, performed a very fast homogenization and extraction, and again detected chloramphenicol in the extract by silica gel chromatography. The activity spectrum of this material was the same as the previous sample. Extraction of the sea water in which the animals were shipped gave no indication of chloramphenicol, thus ruling out external contamination, but not eliminating the possibility that the intestinal microflora of the moon snail might be the source of the antibiotic.

\section{References}

1) Shield, L. S. \& K. L. Rinehart, Jr.: Marinederived antibiotics. in Antibiotics: Isolation, separation and purification. J. Chromatography Library, Vol. 15 . pp. 309 386, M. J. WeINSTEIN \& G. H. WyMAN (Eds.), Elsevier Amsterdam, 1978

2) Newman, D. J.; B. A. Bowie, S. V. B. Fagan, R. T. KING, Jr. \& C. H. NASH, III: A simple device applicable to classification of unknown antibiotics. Abstr. Ann. Meet., Amer. Soc. Microbiol., Abs. Q83, 1980

3) Akagawa, H.; M. Okanishi \& H. Umezawa: Genetics and biochemical studies of chloramphenicol-nonproducing mutants of Streptomyces venezuelae carrying plasmid. J. Antibiotics 32 : $610 \sim 620,1979$ 